American Journal of Infectious Diseases 6 (3): 61-65, 2010

ISSN 1553-6203

(C) 2010 Science Publications

\title{
Idiopathic Granulomatous Mastitis: A Case Report
}

\author{
${ }^{1}$ Mojtaba Varshochi, ${ }^{2}$ Mehdi Haghdoost and ${ }^{2}$ Omid Mashrabi \\ ${ }^{1}$ Department of Infectious Diseases, Tropical Medicine Research Center, \\ ${ }^{2}$ Department of Infectious Disease, Faculty of Medicine, \\ Tabriz University of Medical Sciences, Tabriz, Iran
}

\begin{abstract}
Problem statement: Granulomatous Lobular Mastitis (GLM) or autoimmune mastitis is a rare and benign disease which, except one case reported in an old man, is usually seen during pregnancy or lactation period. This disease was described for the first time by Kessler. Approach: Our case is a 34 year-old woman who has a child with a history of using OCP that primary complaint was swelling, heat and erythema in the right breast. She was diagnosed with mastitis and treated with antibiotics for one month, later on she had experienced stiffness in the breast and a mass was also palpable. The patient was performed surgical drainage and treated with wide spectrum antibiotics being diagnosed with abscess. After one month, a solid mass was palpable so, mammography was performed and the mass was surgically resected with a suspicion of tumor. Results: The pathology report revealed granulomatous mastitis with non caseified granuloma. For Anti-TB treatment was started as medication regime and after 40 days fistula with frequent secretions appeared. Antituberculosis medications stopped and other conditions resulting in none caseified granuloma. In microscopic view granulomatous mastitis along with abscess was reported. Corticosteroids were started and the mass became smaller gradually, the fistula also closed and secretions dried out. Conclusion: Granulomatous Lobular Mastitis is a benign inflammatory breast disease. Cause of disease is still unknown, but some factors have been suggested such as local autoimmune, reaction to the delivery, previous use of contraceptives and infectious causes. The best treatment proposed is corticosteroid therapy in which the mass dwindle and the fistula is closed and secretions dried. The case is now under treatment with corticosteroids and all her symptoms have improved.
\end{abstract}

Key words: Granulomatous lobular mastitis, fistula, breast cancer

\section{INTRODUCTION}

Granulomatous Lobular Mastitis (GLM) or autoimmune mastitis is a rare and benign disease which, except one case reported in an old man, is usually seen during pregnancy or lactation period. (Heer et al., 2003; Goldberg et al., 2000) Idiopathic granulomatous mastitis is a rare and benign breast disease which was described by Kessler and Wolloch (1972) for the first time in 1972. The etiology of this disease is known as chronic, necrotizing granulomatous lobulitis and is similar to breast carcinoma regarding clinical features. Kessler and Wolloch (1972) suggested an autoimmune based etiology for idiopathic granulomatous mastitis however pathogenesis is still unknown. Most patients are in their fertility age. The most common clinical finding is a solid ipsilateral in the breast. In pathology studies, granulomatous inflammation can be seen which mostly affects breast lobules primarily (Ozturk et al., 2009).

\section{MATERIALS AND METHODS}

Case: Our case is a 34 year-old woman who has a child with a history of using OCP. The patient's primary complaint was swelling, heat and erythema in the right breast. She was diagnosed with mastitis and treated with antibiotics for one month, later on she had experienced stiffness in the breast and a mass was also palpable. The patient was performed surgical drainage and treated with wide spectrum antibiotics being diagnosed with abscess. After one month, a solid mass was palpable so, mammography was performed and the mass was surgically resected with a suspicion of tumor.

The pathology report revealed granulomatous mastitis with non caseified granuloma. For Anti-TB treatment was started as medication regime and after 40 days fistula with frequent secretions appeared. This was the time when the patient referred to me and I stopped anti-tuberculosis medications and suggested some tests

Corresponding Author: Mashrabi Omid, Department of Infectious Disease, Faculty of Medicine,

Tabriz University of Medical Sciences, Tabriz, Iran Tel: +98-9144049694/+98-4226226106 
for ruling out other conditions resulting in non caseified granuloma (such as Wegner, sarcoidosis and brucellosis).

Table 1: Results and laboratory finding of patient

\begin{tabular}{ll}
\hline Parameter & Result \\
\hline Ana & Negative \\
Anti_Top(ECL) & 10.15 \\
Wright & Negative \\
Combs wright & Negative \\
Anti Brucella (IgG) & 2.5 \\
CBC & \\
WBC & 9800 \\
RBC & 4.76 \\
Hb & 13.8 \\
Hct & 41.5 \\
PLT & 302000 \\
ESR_1 & 22 \\
ESR_2 & 32 \\
CRP & Negative \\
\hline
\end{tabular}

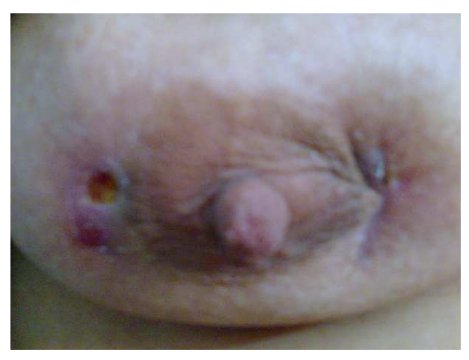

Fig. 1: Photo of breast before treatment

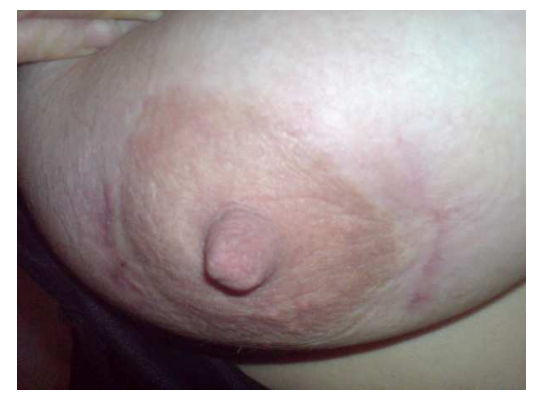

Fig. 2: Photo of breast after treatment

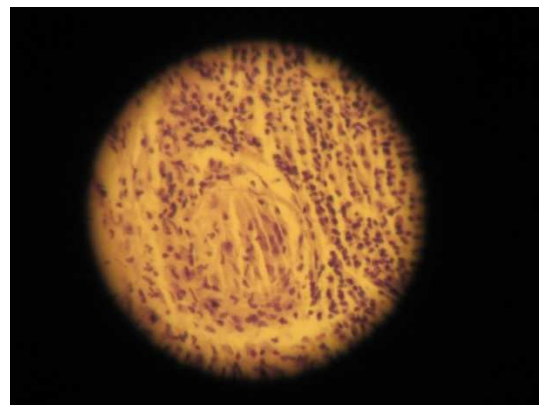

Fig. 3: Image of pathological slides of the patient under study
The results of the performed tests are brought in Table 1. The results of the sputum smears of the patient were also negative in 3 times.

In breast sonography regions with edema associated with tubuloglandular tissues were seen in middle and medial parts of the right breast without distinct margins. No space occupying mass or collection was seen. Pathology studies revealed fragments of breast tissue overlying skin in microscopic view. There were infiltrations of mononuclear inflammatory cells and PMN leukocytes. Non classified granuloma formations along with multinucleated giant cells were also reported in some areas. Mononuclear inflammatory cells had infiltrated the skin. In microscopic view granulomatous mastitis along with abscess was reported. Corticosteroids were started and the mass became smaller gradually, the fistula also closed and secretions dried out. At the time being, the patient is under treatment and all symptoms have been eliminated using corticosteroids. It has been four months since the patient started using corticosteroids. Figure 1-3 demonstrate before and after medication stages and also pathologic views.

\section{RESULTS AND DISCUSSION}

Idiopathic granulomatous mastitis which is also called as autoimmune mastitis and granulomatous lobular mastitis is a benign inflammatory disease of the breast which was described almost 30 years ago. (Heer et al., 2003) The etiology of the disease is unknown but following etiologies have been suggested: local autoimmune reactions, post delivery, previous usage of contraceptives and infectious causes (Ozturk et al., 2009).

Breast cancer is the most common from of malignant disease amongst women (Ngah et al., 2007; Kirova et al., 2006; Lucarelli et al., 2009; Isa et al., 2007; Pulakat et al., 2008).

The disease clinically appears as a painful mass in the breast with diameters of 0.5-9 centimeters in each of the breast quadrants or below areola. The covering skin is usually inflammated (Ozturk et al., 2009; Schelofout et al., 2001) and sometimes nipple is retracted inwardly and lymphadenopathy and adhesion to the underlying Pectoralis muscle is seen. Therefore it is essential to differentiate it from breast carcinoma.

It is believed that this disease is an autoimmune complication of breast tissue which usually occurs in young females who have had delivery (Adams et al., 1987). The most common symptom is a painful breast mass but symptoms like abscess and sinus formation can also be seen. It can imitate breast cancer 
regarding clinical and mammography manifestations. (Adams et al., 1987; Weber et al., 1994; Asoglu et al., 2005; Diesing et al., 2004).

In our study also the patient referred with the primary complications of swelling, heat and erythema and the right breast.

In the review article, the mean age of the patients was 32 years (17-43 years) and the time between disease onsets from delivery was from 1 month before to 15 years (mean of three years). Schelofout et al. (2001) and Kessler and Wolloch (1972) suggested autoimmune process. Some of the authors blame local traumas as probable causes (Ozturk et al., 2009; Cserni and Szajki, 1999).

This disease is diagnosed after ruling out other causes specially breast carcinoma and bacterial infections such as brucellosis, fungal diseases and noninfectious granuloma. Sarcoidosis and tuberculosis mastitis should be born in mind specially when accompanied by erythema (Goldberg et al., 2000). In our study also diagnostic and therapeutic evaluations were carried out to rule out carcinoma and infectious causes such as the tuberculosis. Pathologic evaluations were essential for the definite diagnosis of GLM as mammography or sonography is not able to differentiate GLM from breast cancer or fibro adenoma (Heer et al., 2003; Ozturk et al., 2009). In our study pathologic studies carried out on the mass confirmed GLM diagnosis. In the review of the existing articles, the best cure for GLM is yet not clear. Primary infectious causes have not been completely rejected as initiators of granuloma formation. However the usage of antibiotics is often not helpful, primary medication with corticosteroids has been reported to be helpful. Local resection of the lesion using surgical approach can also be effective however accompanied by complications such as recurrence of the lesion, sinus and sometimes abscess formation (Heer et al., 2003; Ozturk et al., 2009; Goldberg et al., 2000; Cserni and Szajki, 1999). Our patient also experienced abscess and fistula after lesion excision. Sometimes in spite of answering to steroids, the disease relapses which in this case other medications such as Metothrexate can be helpful (Ozturk et al., 2009).

Mammography view of the patient can be seen as symmetric focal densities with irregular margins, irregular mass with speculated borders or multiple bilateral nodules. In sonography, heterogeneous echo mass abscess chambers and tubular structures (fistula like) can be seen. Other diagnostic methods such as Doppler Sonography or MRI are also available (Ozturk et al., 2007). In our study sonographic studies, edematous tissue accompanied by tubuloglandular consolidations and sensitivity without borders were seen in the medial and middle parts of their right breast. No occupying mass or collection was seen. FNA cytologic diagnosis can lead to misdiagnosis of tuberculosis or carcinoma Tse et al. (2003). There is neutrophylic infiltration in the field and a lot of granulomatous histiocytes but definite diagnosis can be achieved through biopsy or excisional biopsy and the result of histopathology (Lai et al., 2005; Verfaillie et al., 2006; Malycha, 2001).

Pathologic view of the disease is described as replacement and destruction of breast cells with non caseified granulomatosis and existence of giant cells, epithelioid cells and macrophage leukocytes in the field (Malycha, 2001). Other systemic granulomatous diseases such as sarcoidosis, Wegner granulomatosis and tuberculosis are ruled out and standard and specific microbiological tests are done (Taghizadeh et al., 2007). Immunohistochemical studies revealed predominantly stromal $\mathrm{T}$ lymphocytes (Brown and Tang, 1979).

At the time being there is no definite accepted treatment for granulomatous mastitis. Wide excision of the lesion is a safe and fast approach until desired cosmetic results are achieved. In the relapsed cases supplementary therapeutic treatment is advised. Taghizadeh et al. (2007) and Akcan et al. (2006) other appropriate choices are as following: oral steroid therapy with a dose of $16 \mathrm{mg}$ daily for 6 weeks and gradual tapering and surgical approach in the relapsed cases (Azlina et al., 2003; Hirata et al., 2003) waiting and conservative approach with short interval follow-up periods (Lai et al., 2005; Diesing et al., 2004) and finally using Metothrexate and Colchicine in cases resistant to corticotherapy. Diesing et al. (2004) and Kim et al. (2003) it is essential to ruled out infectious causes in corticotherapy cases and antibiotic treatment should start before administration of oral steroid in abscess cases. Immunosuppressive treatment should continue until complete remission as there is a $50 \%$ chance of relapse. Long-term follow-up of patients is advised as there is a chance of relapse for long time after medication is ceased. It is not clear yet if long term low dose steroid can prevent relapse or not (Azlina et al., 2003).

Reconstruction is done with delay after first surgery in cases in which wide excision may have led to deformity so that immune suppression treatment course is fulfilled and relapse chance reduced. Reconstruction using prothese has not been advised and it is recommended that tissue reconstruction approaches such as Latismus flap be used (Taghizadeh et al., 2007). 
Complete resection or open biopsy a companied with corticosteroid therapy are the choice treatments for granulomatous mastitis (DeHertogh et al., 1980). Granulomatous mastitis can be accompanied by abscess formation, fistulae and chronic suppuration (Going et al., 1987). Conservative treatment is also recommended in the Fistula treatment (Almasad, 2006).

Also in our study, the patient gave an entirely appropriate response to treatment after treatment with corticosteroids and the mass dwindles gradually and the fistula was closed and secretions dried.

\section{CONCLUSION}

Granulomatous Lobular Mastitis is a benign inflammatory breast disease. Cause of disease is still unknown, but some factors have been suggested such as local autoimmune, reaction to the delivery, previous use of contraceptives and infectious causes. The best treatment proposed is corticosteroid therapy in which the mass dwindle and the fistula is closed and secretions dried. The case is now under treatment with corticosteroids and all her symptoms have improved.

\section{REFERENCES}

Adams, D.H., S.G. Hubscher and D.G. Scott, 1987. Granulomatous mastitis--a rare cause of erythema nodosum. Postgrad. Med. J., 63: 581-582. PMID: 3658869

Akcan, A., H. Akyildiz, M.A. Deneme, H. Akgun and Y. Aritas, 2006. Granulomatous lobular mastitis: A complex diagnostic and therapeutic problem. World J. Surg., 30: 1403-1409. PMID: 16847715

Almasad, J.K., 2006. Mammary duct fistula: Classification and management. ANZ J. Surg., 76: 149-152. PMID: 16626355

Asoglu, O., V. Ozmen, H. Karanlik, M. Tunaci and N. Cabioglu et al., 2005. Feasibility of surgical management in patients with granulomatous mastitis. Breast J., 11: 108-114. PMID: 15730456

Azlina, A.F., Z. Ariza, T. Arni and A.N. Hisham, 2003. Chronic granulomatous mastitis: Diagnostic and therapeutic considerations. World J. Surg., 27: 515-518. PMID: 12715214

Brown, K.L. and P.H.L. Tang, 1979. Postlactational tumoral granulomatous mastitis: A localized immune phenomenon. Am. J. Surg., 138: 326-329. DOI: 10.1016/0002-9610(79)90397-0

Cserni, G. and K. Szajki, 1999. Granulomatous lobular mastitis following drug induce galactorrhea and blunt trauma. Breast J., 5: 398-403. DOI: 10.1046/j.1524-4741.1999.97040.x
DeHertogh, D.A., A.H. Rossof, A.A. Harris and S.G. Economou, 1980. Prednisone management of granulomatous mastitis. N. Engl. J. Med., 303: 799-800. DOI: 10.1056/NEJM198010023031406

Diesing, D., R. Axt-Fliedner, D. Hornung, J.M. Weiss and K. Diedrich et al., 2004. Granulomatous mastitis. Arch. Gynecol. Obstet., 269: 233-236. PMID: 15205978

Going, J.J., T.J. Anderson, S. Wilkinson and U. Chetty, 1987. Granulomatous lobular mastitis. J. Clin. Pathol., 40: 535-540. PMID: 3584506

Goldberg, J., L. Baute, L. Storey and P. Park, 2000. Granulomatous mastitis in pregnancy. Obstet. Gynecol., 96: 813-815. PMID: 11094217

Heer, R., J. Shirmankar and C.D. Griffith, 2003. Granulomatous mastitis can mimic breast cancer on clinical, radiological or cytological examination: A cautionay tale. Breast, 12: 283-286. PMID: 14659315

Hirata, S., T. Saito, K. Kiyanagi, M. Kitada and K. Yamazaki et al., 2003. Granulomatous mastitis diagnosed by core needle biopsy and successfully treated with corticosteroid therapy: A case report. Breast Cancer, 10: 378-381. PMID: 14634520

Isa, N.A.M., E. Subramaniam, M.Y. Mashor and N.H. Othman, 2007. Fine needle aspiration cytology evaluation for classifying breast cancer using artificial neural network. Am. J. Applied Sci., 4: 999-1008. DOI: 10.3844/.2007.999.1008

Kessler, E. and Y. Wolloch, 1972. Granulomatous mastitis: A lesion clinically simulating carcinoma. Am. J. Clin. Pathol., 58: 642-646. PMID: 4674439

Kim, J., K.E. Tymms and J.M. Buckingham, 2003. Methotrexate in the management of granulomatous mastitis. ANZ J. Surg., 73: 247-249. PMID: 12662235

Kirova, Y.M., A. Fourquet, A. Savignoni and B. SigalZafrani, 2006. Risk of Second Non Breast Malignancies (SNBM) in relation to Brca1 and Brca2 mutation status following breast-conserving surgery and radiotherapy. Am. J. Immunol., 2: 61-63. DOI: $10.3844 / .2006 .61 .63$

Lai, E.C., W.C. Chan, T.K. Ma, A.P. Tang and C.S. Poon et al., 2005. The role of conservative treatment in idiopathic granulomatous mastitis. Breast J., 11: 454-456. PMID: 16297091

Lucarelli, A.P., M.M. Martins, V.M. Oliveira, M.A.L. Galvao and J.M. Guedes et al., 2009. HER2 protein overexpression in infiltrating ductal carcinoma of the breast associated with lymph node involvement. Am. J. Applied Sci., 6: 445-448. DOI: $10.3844 / .2009 .445 .448$ 
Malycha, P., 2001. Breast Abscess and Breast Inflammation. In: Breast and Endocrine Surgery, Farndon, J.R. (Ed.). WB Sunders, China, ISBN: 070202144X, pp: 204-206.

Ngah, U.K., S.A. Aziz, M.E. Aziz, M. Murad and N.M.N. Mahdi et al., 2007. A BI-RADS based expert systems for the diagnoses of breast diseases. Am. J. Applied Sci., 4: 865-873. DOI: 10.3844/.2007.865.873

Ozturk, E., M. Akin, M.F. Can, I. Ozerhan and B. Kurt et al., 2009. Idiopathic granulomatous mastitis. Saudi Med J., 30: 45-49. PMID: 19139772

Ozturk, M., E. Mavili, G. Kahriman, A.C. Akcan and F. Ozturk, 2007. Granulomatous mastitis: Radiological findings. Acta Radiol., 48: 150-155. PMID: 17354134

Pulakat, L., R. Kolhe and N. Gavini, 2008. AT1-IRbeta association: A new mechanism for the inhibition of insulin receptor function in breast cancer. Am. J. Biochem. Biotechnol., 4: 24-34. DOI: $10.3844 / .2008 .24 .34$

Schelofout, K., W. Tjalma and I.D. Cooremans, 2001. Observations of an idiopathic granulomatous mastitis. Eur. J. Obstet. Gynecol. Reprod. Bio1., 97: 260-262. PMID: 11451563
Taghizadeh, R., O.P. Shelley, B.K. Chew and E.M Weiler-Mithoff, 2007. Idiopathic granulomatous mastitis: Surgery, treatment and reconstruction. Breast J., 13: 509-513. DOI: 10.1111/j.15244741.2007.00474.x

Tse, G.M., C.S. Poon, B.K. Law, L.M. Pang and W.C. Chu et al., 2003. Fine needle aspiration cytology of granulomatous mastitis. J. Clin. Pathol., 56: 519-521. PMID: 12835297

Verfaillie, G., C. Breucq, R. Sacre C. Bourgain and J. Lamote, 2006. Granulomatous lobular mastitis: A rare chronic inflammatory disease of the breast which can mimic breast carcinoma. Acta Chir. Beig., 106: 222-224. PMID: 16761483

Weber, J.C., D. Gros, G. Blaison, T. Martin, D. Storck and J.L. Pasquali, 1994. Granulomatous mastitis, erythema nodosa and oligoarthritis. Apropos of a case. Rev. Med. Internet, 15: 190-192. PMID: 8059134 